\title{
How Banks Can Self-Monitor Their Lending To Comply with the Equal Credit Opportunity Act
}

\author{
James H. Gilkeson, Drew B. Winters, and Peggy D. Dwyer
}

$\mathbf{T}$ he Equal Credit Opportunity Act (ECOA) prohibits lenders in the United States from discriminating against potential borrowers on the basis of certain demographic characteristics, including gender, marital status, color, race, national origin, and age (assuming the applicant has reached his or her majority). ${ }^{1}$ The ECOA also prohibits discrimination against applicants who receive public assistance income and against those who have exercised rights granted under the Consumer Credit Protection Act or comparable state laws. The ECOA is implemented through Regulation B (Reg B), which originally prohibited the collection of these demographic data in the loan application process to prevent the information from being used to discriminate against underserved groups. Subsequently, mortgage loans were excluded from this prohibition to conform to the requirements of the Home Mortgage Disclosure Act (HMDA). Recently, Reg B has been modified and now allows lenders to collect certain demographic data-namely, race, color, religion, national origin, and gender - if done for the purpose of conducting the kinds of self-tests described in the revised regulation, including selfmonitoring of the commercial lending process for compliance with the ECOA.

Self-monitoring of the lending process for equal credit access will be a new endeavor for most lenders. This paper describes one way for a lender to implement self-monitoring of its lending process, including data collection, data analysis, and interpretation of the results. In addition, we discuss some of the problems inherent in self-monitoring and why there is a constructive role in this process for regulatory oversight.

\footnotetext{
1 Some demographic data can be collected and used during the loan application process (e.g., geographic data such as street address or census tract).

James H. Gilkeson is an associate professor, Drew B. Winters is an associate professor, and Peggy D. Dwyer is an associate professor at the University of Central Florida. The authors thank Bob Avery, Dave Blackwell, Robert Cook, Bill Gavin, Alton Gilbert, Richard Hofler, Tom Lindley, John List, Andy Meyer, and Tim Yeager for comments.

(1) 2003, The Federal Reserve Bank of St. Louis.
}

We focus on the primary question that bank examiners and regulators ask to determine whether a lender is in compliance with the ECOA: Are traditionally underserved groups given the same access to credit by this lender as traditionally well-served (majority) groups? The objective of this paper is to show lenders how to examine their loan process and its outcomes to determine whether they are providing equal access.

During our discussion, we will introduce empirical (statistically based) tests that lenders can use to self-monitor their loan process. We will provide examples of these tests using data from the 1993 Survey of Small Business Finances. With over 2,000 usable survey responses for this analysis, the amount of data from the survey is roughly equivalent to the pool of business loan applicants at a single, large urban bank. Although the process we describe can be used by all lenders, we will also highlight problems that small lenders in particular might have with self-monitoring.

Before going further, one point must be emphasized: This article will not transform the reader into an expert. We will provide a basic outline of the steps that a self-monitoring process should follow and provide a particular empirical example. Each lender will face its own issues with model development, data collection, statistical estimation, and interpretation of results. Appropriate expertise is required during each of these steps.

We also provide some background on lending discrimination. We then step through the process of self-monitoring a lender's loan practices, providing examples from the survey data along the way. We conclude by discussing some problems of selfmonitoring and indicating why we believe that there remains a constructive role for bank examiners and regulators that complements a lender's selfmonitoring efforts.

\section{BACKGROUND AND MOTIVATION}

In August 1998, the Federal Reserve Board proposed changes to Reg B that would allow lenders to collect previously prohibited demographic data on 
all loan applicants. Following the proposal, the Board of Governors of the Federal Reserve System received a joint agency memo that supports the proposed changes. ${ }^{2}$ The memo makes several key points, two of which relate to self-monitoring of the loan process: first, that previous demographic data collected from mortgage lending (as required by the HMDA) have not been used for discriminatory purposes; second, that the lifting of this prohibition on collecting demographic data on loan applications will facilitate both private sector and government detection and prevention of lending discrimination. The concurring agencies believe these points are important because "evidence indicates that discrimination in business and consumer lending remains a serious problem."

Because the change will allow lenders to selfmonitor for compliance with ECOA, it is important for them to understand existing evidence of discrimination. This section discusses the literature on lending discrimination.

To date, the majority of empirical studies on lending discrimination have focused on the residential mortgage market where, as Nesiba (1996) notes, "Empirical researchers see evidence of racial discrimination in virtually every study [of residential mortgage markets] they conduct." Among these studies is the frequently cited Munnell et al. (1996), commonly known as the Boston Fed study. These authors examine loan approval and rejection data for the Boston metropolitan statistical area that were collected as a result of the HMDA, as well as supplemental information regarding applicants' finances and employment and the property they wished to purchase. Despite substantial credit quality controls in the study, Munnell et al. (1996) find that black and Hispanic applicants were significantly more likely than others to have their mortgage applications rejected.

A reexamination of the Boston Fed data by Hunter and Walker (1996) finds that discrimination occurred only among applicants of marginal credit worthiness. That is, when the rational or profitmaximizing lending decision could have gone either way, black and Hispanic applicants were more likely to be rejected than white applicants. Hunter and Walker (1996) interpret their findings as being con-

\footnotetext{
2 The agencies joining in the memo are as follows: the Department of the Treasury, Department of Justice, Department of Housing and Urban Development, Federal Trade Commission, Comptroller of the Currency, Office of Thrift Supervision, Office of Federal Housing Enterprise Oversight, and Small Business Administration.
}

sistent with the cultural-affinity hypothesis, arguing that, at the margin, lender decisions will favor those borrowers with whom the lenders perceive a shared background and culture.

The recent large-scale mortgage lending studies do not report evidence of gender-based discrimination. However, researchers find evidence of genderrelated discrimination in other types of lending. In a study of consumer lending by Texas finance companies, Elliehausen and Lawrence (1990) find evidence of discrimination against a subset of female applicants. Specifically, they identify an interaction of gender and marital status on lending decisions that is suggestive of discrimination against divorced women and widows, but not against divorced men or widowers. ${ }^{3}$

Empirical research on business-lending discrimination has been lacking because of the paucity of data, and we are aware of only two studies on this subject. In 1987, the Federal Reserve began a survey of small business finances, which included survey questions about small business banking activities such as loan requests and denials. The Federal Reserve has continued to monitor small business finances, with additional surveys in 1993 and 1998. One of the studies in question-Cavalluzzo and Cavalluzzo (1998) - uses the 1987 survey; the otherCavalluzzo, Cavalluzzo, and Wolken (2002) - uses the 1993 survey. Both studies can be described as identifying lending discrimination against minorityowned small businesses, but only at the margin. Cavalluzzo and Cavalluzzo (1998) find that minorityowned small businesses are more likely to be denied the full amount of their credit request than whitemale-owned small businesses. Cavalluzzo, Cavalluzzo, and Wolken (2002) show that in competitive banking markets minority-owned small businesses are denied loans at a rate of 39 percent, whereas whitemale-owned businesses of similar credit quality are denied loans at a rate of 32 percent.

As seen above, recent evidence indicates lending discrimination at the margin. In other words, after careful credit analysis and when the lending decision can go either way (i.e., when it is at the margin), members of underserved groups are denied credit more frequently than members of the majority. For compliance with the ECOA, lenders need to

\footnotetext{
3 In contrast to the Elliehausen and Lawrence (1990) findings, Peterson (1981) reported no evidence of gender-based discrimination in consumer lending. However, Peterson's (1981) approach of using ex post data on loans charged off as losses to infer discrimination has been criticized in subsequent research as inappropriate.
} 
show that their lending decisions are based solely on credit quality and are not influenced by group membership. Loan applications tend to divide easily into one of three decision categories: clearly accept, clearly reject, and uncertain. The recent literature suggests that the clearly accept and clearly reject decisions are not influenced by prohibited demographic characteristics. However, as we noted, the decisions ultimately reached for the uncertain category of applications appear to be less favorable for underserved groups, making self-monitoring both important and difficult.

Self-monitoring is important because lenders attempting to comply with the ECOA have no chance of identifying marginal discrimination in their loan processes without the ability to collect demographic data. Self-monitoring for compliance is difficult because problems likely occur in those lending decisions where even a careful credit analysis will not provide a certain decision on whether to accept or reject the loan application. When self-monitoring, the lender will first have to determine whether they have a problem at the margin (and evidence suggests that there is a positive probability of this) and then determine how to remove demographic factors from the uncertain lending decisions so that underserved groups get the same "benefit of the doubt" that the majority receives.

\section{THE CREDIT ANALYSIS PROCESS AND ITS INPUTS}

Now that we have identified the key issue in self-monitoring, we begin the discussion of the loan process itself. We refer to monitoring the process instead of monitoring the loan portfolio because a lender's portfolio includes only the loan applicants that the lender has accepted, whereas self-monitoring must also examine the loan applicants that the lender rejects. Throughout this discussion, we will continue to refer to self-monitoring of the process - and not the portfolio - to avoid any tendencies on the part of the reader to consider a specific portfolio.

An important theme of the self-monitoring process is don't panic. We have already introduced a number of issues to consider, with more to come; but self-monitoring is not an insurmountable task for an individual lender. We describe here some fairly basic analysis that can make self-monitoring a reasonable task.

The first step in the self-monitoring process is to identify potentially underserved applicant groups.
Typically, these are traditionally underserved groups such as businesses owned by women and racial and ethnic minorities, but the list will vary from lender to lender, depending on the demographics of its applicant pool. Once a list of groups is determined, any application not coming from one of the potentially underserved groups is deemed to be from the majority, or control group, which is assumed to be well-served. The 1993 Survey of Small Business Finances provides demographic information about each business's owners that allows the owners to be categorized into the majority or one or more of three traditionally underserved demographic groups: females, minorities (which includes blacks, Asians, Pacific Islanders, Native Americans, and Alaska Natives), and Hispanics. In this case, the control group is businesses owned by white males. In the survey, a business is classified as owned by members of a specific group only if more than 50 percent of its equity is owned by members of that group. This is fairly stringent compared with rules that have been used to classify ownership for various government programs (particularly those related to government purchasing). ${ }^{4}$ However, the rule does exclude small businesses that are owned jointly (50-50) by a husband and wife, which is appropriate because a lender inclined toward discrimination would be unlikely to view such a business as being female owned.

The next step in the process is to gather basic information from all loan applications submitted to the lender. Because the primary question being asked is whether potentially underserved groups are given the same access to credit by the lender as traditionally well-served (majority) groups, it is critically important to know whether the loan application was accepted or rejected, as well as whether the applicant belongs to one or more of the potentially underserved groups. The 1993 Survey of Small Business Finances asked respondents "What was the outcome of the most recent credit application by the business?" and allowed one of two answers: approved or denied. Table 1 summarizes answers to this question by the owner's demographic group. The results show that white-male-owned small businesses were approved 89.04 percent of the time, while Hispanic-owned firms were approved at a rate of 84.38 percent, female-owned firms at a rate

\footnotetext{
4 Until recently, Reg B prohibited collection of certain demographic data. We expect that, as self-monitoring begins to occur, regulators will provide guidance as to an appropriate ownership rule.
} 


\section{Table 1}

\section{Credit Availability by Business-Ownership Classification}

\begin{tabular}{|c|c|c|c|c|}
\hline & $\begin{array}{c}\text { Female-owned } \\
\text { firms }\end{array}$ & $\begin{array}{c}\text { Minority-owned } \\
\text { firms }\end{array}$ & $\begin{array}{c}\text { Hispanic-owned } \\
\text { firms }\end{array}$ & $\begin{array}{c}\text { White-male-owned } \\
\text { firms }\end{array}$ \\
\hline \multicolumn{5}{|c|}{ What was the outcome of the most recent credit application by the business? } \\
\hline Approved & $78.57 \% *$ & $59.92 \% *$ & $84.38 \%$ & $89.04 \%$ \\
\hline Denied & $21.43 \%$ & $40.08 \%$ & $15.63 \%$ & $10.96 \%$ \\
\hline No. of responses & 294 & 257 & 96 & 1424 \\
\hline
\end{tabular}

NOTE: *Indicates business-ownership differences between females and white males, minorities and white males, and Hispanics and white males at the 1 percent level using a $\chi^{2}$ test.

of 78.57 percent, and minority-owned firms at a rate of 59.92 percent. These acceptance rates show why female-, minority-, and Hispanic-owned businesses are referred to as underserved groups and would likely be a reason for examiners to thoroughly investigate the particular loan product or market in which such disparities arose. A lender engaged in self-monitoring who sees similar disparities will need to show that its loan process is in compliance with the ECOA, which requires showing that the different approval rates occur because of different levels of credit quality between demographic groups. This issue is the focus of the remainder of this article.

The process of demonstrating credit quality differences begins by defining the lender's credit analysis process and the inputs used in the process. Each lender analyzes credit a little differently, and so we must clearly define their process and the inputs they use. This is extremely important because the inputs defined here become the control variables used later in the analysis of the lender's loan process.

A good starting point that we think all lenders can agree on is that they make loans that they believe will be repaid in accordance with the loan contract. The question that arises is: What do lenders analyze to make this lending decision? In theory, lenders analyze the future cash flows of the loan applicant over the life of the proposed loan to determine whether the cash flows are sufficient to repay the loan. However, without a crystal ball, lenders have no way of knowing the future cash flows of the loan applicant, so they must examine other variables (proxies) that they believe indicate their likely repayment behavior. Identifying these proxy variables is a big step in the self-monitoring effort.

Each lender will use a different set of proxy variables, so it is important for each lender to identify the inputs they use in their loan decision process. For each variable identified, a brief description of how it provides information about future repayment behavior should be created. This is important in demonstrating compliance with the ECOA-that underserved groups do get equal access to credit from the lender in question. In other words, the lender must demonstrate that its credit decisions are based on the credit quality of the loan applicant without regard to demographic characteristics.

Lenders should be aware that examiners recognize three types of evidence when determining whether lending discrimination has occurred. The first is overt evidence of disparate treatment, which occurs when a lender openly discriminates on a prohibited basis. The second is comparative evidence of disparate treatment, which occurs when a lender treats one credit applicant differently from others based on a prohibited basis. The third is disparate impact, which occurs when a lender applies an otherwise neutral policy or practice equally to all credit applicants, but the policy or practice disproportionately excludes or burdens certain persons on a prohibited basis. This third type of evidence means that lenders must be careful in arguing that denials based on nondiscriminatory factors are lawful, if such factors disproportionately affect certain underserved groups.

A word of warning at this point. Each lender should spend some time identifying a complete list of input variables. The reason is that the lender must collect these variables from every loan application and then record these variables in a database to be used for self-monitoring. Whenever there is doubt about whether a variable is truly an important part 
of the decision process, the variable should be collected for the database. It is much easier to delete unnecessary variables from the analysis later in the process than it is to add a missing variable to the database. In the remainder of this section we define the variables we use in our example and discuss how they relate to credit quality.

\section{Credit Quality Variables}

It is important to note that the set of variables we discuss here must not be viewed as the definitive set of credit quality variables. Instead, they should be seen as one viable set of variables identified by a particular lender to describe its own credit analysis process. In particular, while we chose a set of variables that are collected in most credit applications, our choice of variables is constrained by the data available in the survey. A self-monitoring lender is not constrained in this manner because the lender defines the variables that describe its loan analysis process and then collects data on those variables out of its own loan application files for its selfmonitoring database.

Each lender must identify the variables it uses for credit analysis and then define how each variable relates to credit quality. Lenders should be able to do this, but may feel uncomfortable with the process. Academic literature and banking textbooks should be helpful, and there is a multitude of sources for reference. Commercial banking is based on the business of evaluating loan applications, so bank management texts tend to provide extensive coverage of the topic (e.g., Koch, 1995, Chap. 21). Ongoing development and use of automated credit scoring models provides another source of the structure and content of such models (e.g., Saunders, 1999). In addition, a number of researchers have developed similar models in their work (e.g., Blackwell and Winters, 1997; Melnik and Plaut, 1986; and Petersen and Rajan, 1995).

Since we are not lenders actively involved in credit analysis, we begin by finding a model of credit quality in the academic literature and then adapt that model to the variables available in the survey. We employ the linear model of credit quality control variables used in Petersen and Rajan (1994). We find this model to be particularly appropriate for our study because it was used to examine the 1987 Survey of Small Business Finances and is therefore easily adapted to our data and to the data normally available to lenders. Petersen and Rajan's model includes a number of measures intended to capture three categories of applicant characteristics: investment opportunities, cash flow quality, and existing banking relationships. In our analysis, we include a total of 18 credit quality variables; as more fully discussed later, two of these capture the firm's investment opportunities, ten capture cash flow quality, and the remaining six measure the firm's existing banking relationships. These individual variables are listed in Table 2 and are described below, along with their expected impact on the lending decision.

A firm's investment opportunities are proxied for by its size and age, both of which are expected to have positive effects on its credit quality. Larger firms have better internal diversification than smaller firms and can therefore better survive either a failed project or declining economic conditions. Older firms have an established performance record and are more likely to have experienced owners and upper management.

A firm's cash flow quality is measured using a variety of proxies. The level of equity is a rough proxy for the owners' investment in the firm; in the banking literature, this measure is often used to indicate the amount of cushion the firm has to absorb business losses without defaulting on loans. Equity should have a positive impact on credit quality because more equity implies more protection for creditors. In contrast, leverage measures the size of a firm's debts relative to its total size. Higher leverage increases the likelihood of default; therefore, leverage should be negatively related to credit quality. In addition, sales is a direct measure of business health and should be positively related to credit quality. ${ }^{5}$ Profits is another common measure of cash flow quality that lenders should consider for their control variables. However, as is fully discussed later, we cannot include both sales and profits in our model because these variables are too highly correlated. We chose to include sales because it fits better with our data, so we do not fully describe a profit variable. However, this is one of those examples where a lender should collect both variables when building a self-monitoring database and then later choose which variable to use in the analysis.

The remaining proxies for cash flow quality are dummy variables (binary variables) that take on a value of 0 or 1 . In general, we assign a value of 1 to a dummy variable if the condition it represents is true. For instance, the next variable we discuss is

\footnotetext{
5 In other literature, sales is often used as a proxy for firm size. Regardless of the interpretation, sales is typically expected to be positively associated with credit quality.
} 


\section{Table 2}

Variable Definitions and Their Anticipated Impact on the Probability of Loan Approval

Variable

Dependent variable

Test variables

Female

Minority

Hispanic

Control variables

Investment opportunities

Size

Age

Cash flow quality

Equity

Leverage

Sales

Leases

Trade credit denied

Owner delinquent

Business delinquent

Accounts receivable

Inventory

Corporation

Banking relationship

Business checking

Credit card

Line of credit

Vehicle loans

Equipment loans

MSA location

Description

Expected impact

"Was the most recent credit application approved or denied?" 0/1 dummy $=1$ if application was approved

$0 / 1$ dummy $=1$ if more than 50 percent of the business is owned by females

$0 / 1$ dummy $=1$ if more than 50 percent of the business is owned by blacks, Asians, Pacific Islanders, Native Americans, or Alaska Natives

$0 / 1$ dummy $=1$ if more than 50 percent of the business is owned by Hispanics

Natural log of business's total assets

Natural log of business's age in years

$+$

$+$

Business's total equity (in \$millions)

(Total assets - total equity)/total assets

Business's 1992 total sales (in \$millions)

$0 / 1$ dummy $=1$ if the business has any leases

$0 / 1$ dummy $=1$ if any supplier has denied the business trade credit within the last 3 years

$0 / 1$ dummy $=1$ if the principal owner of the business has been $60+$ days delinquent on any obligation within the last 3 years

$0 / 1$ dummy $=1$ if the business has been $60+$ days delinquent on any obligation within the last 3 years

$0 / 1$ dummy $=1$ if the business has accounts receivable

$0 / 1$ dummy $=1$ if the business has inventory

$0 / 1$ dummy $=1$ if the business is a corporation

0/1 dummy $=1$ if the business has a checking account

$0 / 1$ dummy $=1$ if the business has one or more credit cards

$0 / 1$ dummy $=1$ if the business has one or more lines of credit

$0 / 1$ dummy $=1$ if the business has one or more vehicle loans

$0 / 1$ dummy $=1$ if the business has one or more equipment loans

$0 / 1$ dummy $=1$ if the business is located within an MSA, suggesting a more competitive banking environment

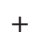

$-$

$+$

?

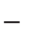


leases. As a dummy (binary) variable, leases equals 1 if the firm in question has any business leases. The relationship between this variable and credit quality is ambiguous. One the one hand, a firm that has existing leases has already proven itself to be credit worthy, suggesting a positive relationship. On the other hand, leases allow a firm to use various assets on a long-term basis without necessarily recognizing ownership of the assets or the debt payments required by the lease (i.e., some leases represent off-balance-sheet financing). The presence of leases means that our leverage variable (which should have a negative impact on credit quality) is understated, suggesting that leases could have a negative impact on credit quality in some cases. The next three variables, trade credit denied, owner delinquent, and business delinquent, are measures of existing problems with the firm's credit quality and should be negatively related to the lending decision because, not surprisingly, firms with credit problems should be less worthy of receiving new loans.

It should be noted that the "trade credit denied" variable may bias our tests against a finding of noncompliance with the ECOA, but we still include this variable because it is information that is commonly collected on business loan applications and used by lenders to screen loan applicants. However, if discrimination influences all types of credit decisions, denial of trade credit that was influenced by discrimination could be misinterpreted by our tests as a rational basis for denial of the most recent loan application. ${ }^{6}$ Bank examiners and regulators will be concerned about the potential bias. For variables like trade credit denied that may bias empirical results, the analysis should be done with and without the variable in question to determine its impact on the test results for equal access to credit for the underserved groups. We show later that the trade credit denied variable is significant in our regression model, but note here that removing the trade credit denied variable from our regression model does not alter our results or conclusions regarding access to credit for traditionally underserved groups.

Levels of accounts receivable and inventory are two other indicators of cash flow quality. Both accounts receivable and inventory should be positively related to credit quality because they indicate assets that can be converted to cash relatively easily

\footnotetext{
6 In a simple test that regresses the "trade credit denied" dummy against borrower age, size, and minority status, firms of all ages and sizes that are owned by minorities are significantly more likely to have been denied trade credit.
}

(i.e., liquid assets) and assets that are commonly pledged as collateral in business lending. Finally, the firm type (corporation versus sole proprietorship or partnership) is included because of prior evidence that corporations are less likely to default on business loans than other types of organizations.

The firm's existing banking relationships are proxied by a series of dummy variables that measure whether the firm has a business (versus personal) checking account, a business credit card, a line of credit, vehicle loans, or equipment loans. Most banks practice "relationship lending" in which they are more likely to lend to existing customers; thus, any sign of an existing banking relationship should be positively related to loan approval. Further, the existence of current loans suggests that the firm has already passed earlier credit quality screens and is worthy of credit. Lenders commonly acquire information about existing credit during the application process, both to ensure that the applicant is not overextended and to see whether other lenders have "pre-certified" the applicant. ${ }^{7}$

In addition to these banking relationship variables, we also include a dummy that equals 1 if the firm is located within a metropolitan statistical area: A more metropolitan setting implies more competition (more banks and other lenders), which typically means that lenders are more likely to approve applicants of a given credit quality. This variable may not be needed by all lenders, but lenders with multiple locations should consider a variable such as this to control for the variability in the level of competition across its different bank locations. ${ }^{8}$ Including metropolitan statistical areas in our model allows us to control somewhat for the competitive nature of the local banking market.

We close our discussion of credit quality variables with two reminders. First, the control variables for credit quality that we include in our model are by no means exhaustive. However, it is not our intent to include every possible variable in the model. Instead, we develop a set of variables that should measure credit quality and that are part of the normal data collection process for a loan application. Our intent is to provide an example of a credit quality model that lenders could easily use to self-monitor

\footnotetext{
7 Although having too many existing loans could be viewed in a negative way, we already control for that with the leverage variable.

8

Blackwell and Winters (2000) show that different levels of local competition across different bank locations within a bank holding company affect the loan rate offered at each location, with the less-competitive locations offering higher loan rates.
} 


\section{Table 3}

Summary Statistics of Credit Quality Variables (Means and Percentages of Yes Answers)

\begin{tabular}{|c|c|c|c|c|c|c|c|c|c|c|}
\hline \multirow[b]{2}{*}{ Variables } & \multicolumn{2}{|c|}{ All firms } & \multicolumn{2}{|c|}{$\begin{array}{l}\text { Female-owned } \\
\text { firms }\end{array}$} & \multicolumn{2}{|c|}{$\begin{array}{l}\text { Minority-owned } \\
\text { firms }\end{array}$} & \multicolumn{2}{|c|}{$\begin{array}{l}\text { Hispanic-owned } \\
\text { firms }\end{array}$} & \multicolumn{2}{|c|}{$\begin{array}{c}\text { White-male-owned } \\
\text { firms }\end{array}$} \\
\hline & Approve & Deny & Approve & Deny & Approve & Deny & Approve & Deny & Approve & Deny \\
\hline Total assets & $\$ 3,542,593$ & $\$ 742,090$ & $\$ 1,519,421$ & $\$ 456,548$ & $\$ 1,024,233$ & $\$ 234,458$ & $\$ 701,202$ & $\$ 392,893$ & $\$ 4,297,026$ & $\$ 1,134,360$ \\
\hline Age (yr) & 16.27 & 11.29 & 13.56 & 10.35 & 12.10 & 9.14 & 14.44 & 10.87 & 17.22 & 12.74 \\
\hline Equity & $\$ 1,228,498$ & $\$ 111,447$ & $\$ 481,875$ & $\$ 121,382$ & $\$ 311,580$ & $\$ 99,714$ & $\$ 414,631$ & $\$ 147,032$ & $\$ 1,497,121$ & $\$ 117,309$ \\
\hline Leverage & $44.84 \%$ & $68.02 \%$ & $87.26 \%$ & $60.31 \%$ & $55.25 \%$ & $65.14 \%$ & $21.45 \%$ & $81.63 \%$ & $39.35 \%$ & $82.99 \%$ \\
\hline Sales & $\$ 7,378,312$ & $\$ 1,530,285$ & $\$ 4,153,528$ & $\$ 502,793$ & $\$ 2,575,238$ & $\$ 626,414$ & $\$ 2,336,552$ & $\$ 1,217,826$ & $\$ 8,772,085$ & $\$ 2,401,917$ \\
\hline $\begin{array}{l}\text { Accounts } \\
\text { receivable }\end{array}$ & $77.46 \%$ & $64.74 \%$ & $67.53 \%$ & $55.56 \%$ & $73.38 \%$ & $62.14 \%$ & $66.67 \%$ & $66.67 \%$ & $80.05 \%$ & $69.87 \%$ \\
\hline Inventory & $67.14 \%$ & $63.46 \%$ & $63.20 \%$ & $50.79 \%$ & $59.74 \%$ & $57.28 \%$ & $61.73 \%$ & $53.33 \%$ & $68.45 \%$ & $71.79 \%$ \\
\hline Leases & $23.19 \%$ & $27.56 \%$ & $15.58 \%$ & $25.40 \%$ & $21.43 \%$ & $20.39 \%$ & $16.05 \%$ & $20.00 \%$ & $25.00 \%$ & $31.41 \%$ \\
\hline $\begin{array}{l}\text { Trade credit } \\
\text { denied }\end{array}$ & $7.91 \%$ & $24.04 \%$ & $11.26 \%$ & $25.40 \%$ & $15.58 \%$ & $21.36 \%$ & $8.64 \%$ & $20.00 \%$ & $6.47 \%$ & $25.64 \%$ \\
\hline $\begin{array}{l}\text { Owner } \\
\text { delinquent }\end{array}$ & $8.91 \%$ & $32.69 \%$ & $12.99 \%$ & $33.33 \%$ & $23.38 \%$ & $46.60 \%$ & $16.05 \%$ & $13.33 \%$ & $6.62 \%$ & $25.64 \%$ \\
\hline $\begin{array}{l}\text { Business } \\
\text { delinquent }\end{array}$ & $20.71 \%$ & $46.15 \%$ & $24.24 \%$ & $42.86 \%$ & $35.71 \%$ & $48.54 \%$ & $20.99 \%$ & $26.67 \%$ & $18.38 \%$ & $46.15 \%$ \\
\hline Corporation & $46.31 \%$ & $34.29 \%$ & $37.66 \%$ & $26.98 \%$ & $46.10 \%$ & $31.07 \%$ & $40.74 \%$ & $33.33 \%$ & $47.79 \%$ & $36.54 \%$ \\
\hline Checking & $99.47 \%$ & $95.19 \%$ & $99.13 \%$ & $93.65 \%$ & $98.05 \%$ & $91.26 \%$ & $100.00 \%$ & $86.67 \%$ & $99.68 \%$ & $98.08 \%$ \\
\hline Credit card & $41.30 \%$ & $34.29 \%$ & $41.99 \%$ & $33.33 \%$ & $40.26 \%$ & $34.95 \%$ & $41.98 \%$ & $26.67 \%$ & $41.01 \%$ & $33.97 \%$ \\
\hline Credit line & $65.13 \%$ & $27.56 \%$ & $54.55 \%$ & $22.22 \%$ & $51.30 \%$ & $24.27 \%$ & $58.02 \%$ & $13.33 \%$ & $68.69 \%$ & $32.05 \%$ \\
\hline Vehicle & $35.34 \%$ & $32.69 \%$ & $35.50 \%$ & $28.57 \%$ & $35.71 \%$ & $31.07 \%$ & $38.27 \%$ & $40.00 \%$ & $35.17 \%$ & $35.26 \%$ \\
\hline Equipment & $30.38 \%$ & $27.56 \%$ & $24.68 \%$ & $30.16 \%$ & $25.32 \%$ & $22.33 \%$ & $28.40 \%$ & $20.00 \%$ & $32.26 \%$ & $29.49 \%$ \\
\hline MSA & $77.05 \%$ & $85.90 \%$ & $77.49 \%$ & $84.13 \%$ & $91.56 \%$ & $94.17 \%$ & $83.95 \%$ & $86.67 \%$ & $75.24 \%$ & $80.77 \%$ \\
\hline
\end{tabular}

NOTE: MSA is metropolitan statistical area.

their loan process. Second, our list of control variables should not be considered the definitive list of variables to be used in self-monitoring; instead, it should be considered illustrative of the types of variables to include. We believe our chosen set of variables describes the factors considered by small business lenders when evaluating loan requests. However, every lender evaluates credit a little differently, so the control variables used for selfmonitoring should describe the factors each lender uses in their own credit-granting decision process.

\section{Summary Statistics for the Control Variables}

Once the control variables are chosen, it is a good idea to look at summary statistics of the control variables. The summary statistics, which will pool accepted and denied loan requests according to ownership group, begin to describe the creditgranting decision process; but summary statistics must be viewed only as a first step and not as the end of the journey. Summary statistics, it should be noted, do not allow for the multi-dimensional relationships between variables that occur in a lender's decision process, which we capture later in a regression. We report summary statistics for the control variables in Table 3.

For the continuous variables, we report means or averages, which is a common choice, as the goal of reporting a summary statistic is to provide a representative number for the variable in the data set. A viable alternative to the mean is the median, which provides a better measure of a representative num- 
ber when the data are skewed. (Data are skewed when the mean or average value is closer to one end of the range of values in the data than the other.) The data for the continuous variables do not appear to be highly skewed, so we chose to report means. For the binary variables that record yes or no (true or false) answers, we report the percentage of yes answers. Note that the form presented in Table 3 is not necessarily the form used in the statistical estimation. For example, we report the mean total assets, but use the natural log of total assets in our tests, as discussed in the previous section.

In each grouping of firms, we see the expected relationship for approved versus denied loan requests across all the continuous variables. That is, within each group, the firms that had their loan requests approved have more assets, more equity, more sales, and less leverage and are older than the firms that had their loan requests denied. (An exception to the expected relationships is the leverage variable for female-owned businesses; however, a closer look showed that leverage for female-owned businesses is highly skewed.) The binary variables are also generally consistent with our expectations. More accounts receivable and inventory are associated with approved loans, whereas previous credit problems are related to loan denials. Also, previous banking relationships are generally positively related to loan approvals. However, the summary statistics are different enough across groups that it is impossible to determine whether group membership plays a role in the credit-granting decision without using a process that considers the joint effects of all of the credit quality variables along with the group membership.

In summary, the basic statistics are designed to provide a first-pass description of the data. In this case, the basic statistics reported in Table 3 suggest that the relationship between the credit-granting decision (approval or denial) and each variable is consistent with our expectations. This further suggests that the variables describe at least some part of the credit evaluation process. If a variable appears to have the opposite effect from what is expected, a closer look at the variable might be needed to root out possible input problems, such as a calculation error or an unusual observation (i.e., an outlier). Another consideration would be whether the variable measures an effect that is different from the intended effect. Measuring a different effect does not mean the variable should be removed from the analysis, but instead warns us that we may need to add additional variables because some component of the credit evaluation may have been omitted from our set of variables.

In the next section, we combine the variables in a regression model to determine whether the preliminary relationships between each variable and the credit-granting decision hold up when we let the variables work together to describe a loan applicant. We will also see whether, after controlling for these credit quality variables, group membership plays a role in the credit-granting decision.

\section{THE PRIMARY SELF-MONITORING TEST FOR COMPLIANCE WITH THE ECOA}

In the previous section, we defined our credit quality variables and calculated summary statistics for them. These statistics indicated that each individual variable tended to relate to credit quality within each demographic group in the manner that we anticipated. However, the variables show large differences between groups that prevent the summary statistics from providing any information about equal access to credit for traditionally underserved groups. Regression methods provide a way to measure how all of the credit quality variables work together to provide information about applicant credit quality and credit access across groups. In this section, we discuss our regression methods and the results from tests using the survey data.

Specifically, our regression is designed to determine whether businesses owned by underserved groups are granted credit at the same rate as whitemale-owned businesses of the same credit quality. Regressions contain three types of variables: dependent variables, test variables, and control variables. Our credit quality variables become the control variables in our regression model because they are designed to control for credit quality differences across businesses. The test variables in each regression are the three business owner group variables (female, minority, and Hispanic), which are binary variables assigned a value of 1 if the business owner is a member of the group and 0 otherwise (for example, a business owned solely by an Hispanic woman would have these values: female $=1$, minority $=0$, and Hispanic $=1$ ). Because we are trying to determine whether traditionally underserved groups have the same access to credit as white males do, the test variables are designed to compare businesses owned by underserved groups with businesses owned by white males. 
The dependent variable is the decision on each business's most recent credit request, which is identified in the survey as approved or denied. This is a binary variable assigned a value of 1 if the credit request was approved and 0 if it was denied. When the dependent variable in a model is a binary variable, the standard (least-squares) regression model is inappropriate. A popular choice in this case, and the one we use here, is the logistic model. Other acceptable choices include the probit model and discriminate analysis.

Before estimating the regressions, we always test for pairwise collinearity among the control (credit quality) variables by estimating a correlation matrix. Previously, we discussed using sales as a credit quality variable. As an alternative to sales, we could use profits. However, profits and sales have a positive correlation of 0.84 , which is large enough for the variables to be considered collinear. (Collinear means that the two variables closely resemble each other-changes in one are closely matched by changes in the other.) Collinearity is a problem in regressions because it causes the over-estimation of variances, which biases the test statistics against findings of significance. This creates the error of concluding that no relationship exists when, in fact, one does. The most common solution to the collinearity problem is to remove one of the variables from the regression model. We chose to report results using sales and excluding profits from the control variables because sales provided greater significance as a credit quality control variable. Replacing sales with profits in our tests does not qualitatively change the results we present. The largest remaining correlation is +0.48 , between total assets and total sales. Correlations of less than 0.50 between control variables in a regression are generally considered acceptable. The point being made here is that, before estimating any regression model, a lender must check the correlations between all the credit quality variables and usually remove one variable from each pair with a correlation of greater than 0.50 .

\section{Loan Denial Regression Results}

Our test of the loan process consists of three logistic regressions that examine the impact of female, minority, and Hispanic ownership on credit decisions. The dependent variable is the respondent's answer to the question "What was the outcome of the most recent credit application by the business?"; this is coded as a dummy variable, with 1 indicating acceptance of the application and 0 indi- cating denial of the application. Each of the three test variables for the underserved groups (female, minority, and Hispanic) are set equal to 1 when the business is owned by members of the underserved group and 0 otherwise. When the business ownership group is white males, all three test variables are set equal to 0 . The first of the three tests employs only the three test variables, the second employs the three test variables and the 18 credit quality control variables, and the third employs only the credit quality control variables.

The results of our tests are provided in Table 4. However, before we dive into the discussion of the regression results for compliance with the ECOA, we must discuss how to interpret them. For each control and test variable in a regression model, the computer program calculates two important pieces of information: a test statistic and a parameter estimate. The test statistic tells us how certain or confident we are that the parameter estimate is statistically different from 0 , and the parameter estimate provides the size and direction of the relationship between the control or test variable and the dependent variable. A parameter estimate of 0 means that no relationship exists between a control or test variable and the dependent variable. However, parameter estimates in regressions are seldom exactly equal to 0 , so we use tests to determine whether the parameter estimate is big enough for us to be confident that the real value of the parameter is different from 0 . In our case, the test statistic that we report is a $\mathrm{p}$-value. A p-value of less than 0.10 is generally accepted as evidence that the true parameter value is different from 0 (indicating a relationship between the test or control variable and the dependent variable), with the evidence becoming stronger as the $p$-value decreases in size. ${ }^{9}$ We report $p$-values in parentheses beside each regression parameter estimate.

\footnotetext{
9 Papers often discuss statistical significance levels of 10 percent ( $\mathrm{p}$-value $\leq 0.10), 5$ percent ( $p$-value $\leq 0.05$ ), and 1 percent ( $p$-value $\leq 0.01$ ). A 10 percent significance level suggests 90 percent confidence that the parameter estimate is different from 0 , while a 1 percent significance level suggests 99 percent confidence that the parameter estimate is different from 0 . One problem in statistical analysis is that the sample may not have the same characteristics as the population. When we find, for example, that the percentage of minority-owned businesses with lines of credit differs in our sample from the percentage of whitemale-owned businesses, we cannot be 100 percent certain that the percentages differ in the entire population of businesses. It is possible that our sample is different from the population. A confidence level tells us how certain we are that the differences observed in the sample are representative of the population. A significance level of 10 percent means that we are 90 percent certain that the observed difference is true of the whole population, while a 1 percent significance level indicates 99 percent confidence.
} 


\section{Table 4}

\section{Loan Process Model}

\begin{tabular}{|c|c|c|c|}
\hline & Univariate model & Full model & Control model \\
\hline Intercept & $2.09(0.00)$ & $-1.31(0.13)$ & $-1.85(0.03)$ \\
\hline Female & $-0.40(0.01)$ & $-0.04(0.83)$ & Omitted \\
\hline Minority & $-1.61(0.00)$ & $-0.87(0.00)$ & Omitted \\
\hline Hispanic & $-0.33(0.25)$ & $0.00(0.99)$ & Omitted \\
\hline Size & & $0.13(0.01)$ & $0.15(0.00)$ \\
\hline Age & & $0.23(0.03)$ & $0.26(0.01)$ \\
\hline Equity & & $0.16(0.02)$ & $0.16(0.02)$ \\
\hline Leverage & & $-0.02(0.65)$ & $-0.02(0.67)$ \\
\hline Sales & & $0.04(0.04)$ & $0.04(0.03)$ \\
\hline Leases & & $-0.69(0.00)$ & $-0.63(0.00)$ \\
\hline Trade credit denied & & $-0.90(0.00)$ & $-0.91(0.00)$ \\
\hline Owner delinquent & & $-0.39(0.07)$ & $-0.51(0.02)$ \\
\hline Business delinquent & & $-0.68(0.00)$ & $-0.73(0.00)$ \\
\hline Accounts receivable & & $0.27(0.14)$ & $0.26(0.15)$ \\
\hline Inventory & & $-0.08(0.68)$ & $-0.05(0.82)$ \\
\hline Corporation & & $0.23(0.19)$ & $0.16(0.34)$ \\
\hline Business checking & & $1.23(0.04)$ & $1.49(0.01)$ \\
\hline Credit card & & $0.04(0.81)$ & $0.01(0.94)$ \\
\hline Line of credit & & $1.12(0.00)$ & $1.14(0.00)$ \\
\hline Vehicle loan & & $0.05(0.75)$ & $0.07(0.66)$ \\
\hline Equipment loan & & $0.12(0.50)$ & $0.15(0.38)$ \\
\hline MSA location & & $-0.40(0.06)$ & $-0.53(0.01)$ \\
\hline No. approved & 1,695 & 1,462 & 1,462 \\
\hline No. denied & 312 & 270 & 270 \\
\hline Model $\chi^{2}$ & $1,625.66$ & $1,181.09$ & $1,194.92$ \\
\hline Pseudo- $R^{2}$ & $5.65 \%$ & $19.52 \%$ & $18.59 \%$ \\
\hline
\end{tabular}

The first column of Table 4 verifies the summary statistics shown in Table 1. When no control variables are included, we find negative and statistically significant ( $p$-value $<0.10$ ) parameter estimates for female- and minority-owned firms and no significant impact ( $p$-value $>0.10$ ) for Hispanic-owned firms. The real value of this test is to verify that we have set up the logistic model correctly before we add the credit quality control variables.

The second column of Table 4 shows the impact of female, minority, and Hispanic ownership when credit quality is controlled for. Model $\chi^{2}$ and pseudo$\mathrm{R}^{2}$ statistics suggest that our model has significant explanatory power in describing the credit evaluation process. The pseudo- $R^{2}$ statistic suggests that our model explains about 20 percent of the variation in the loan decision process. While this is reasonably good when this type of model is applied to such a large, diverse data set, it also means that much of the underlying loan process remains unexplained by the model.

Next, we look at the control variables to determine whether their parameter estimates are significantly different from 0 and have the expected sign. If the parameter estimates are significant and have the expected sign, our results our consistent with 
the hypothesis that our empirical model describes the underlying loan decision process. ${ }^{10}$ From the continuous variables, we again see, as expected, that larger, older businesses with more equity, more sales, and less leverage were more likely to have their loan requests approved. From the binary (yes/no) variables, we see, as expected, that previous credit problems make it more likely that a loan request will be denied and an existing relationship with a bank or other lender makes it more likely that a loan request will be approved. ${ }^{11}$ With these controls in place, female ownership of a business does not have a significant impact on the loan decision process. Comparing this result to the average denial rates in Table 1 and the first column of Table 4 suggests that female-owned businesses are less likely to get loan requests approved because they are, on average, less credit worthy. ${ }^{12}$ In contrast, despite these numerous credit quality controls, minority-owned businesses are significantly more likely to have loan applications rejected (as indicated by a negative sign on the parameter estimate and $p$-value of 0.00 ). This suggests that even after controlling for differences in credit quality, the fact that a business is minority owned (blacks, Asians, Pacific Islanders, Native Americans, or Alaska Natives) has a negative impact on the credit-granting decision. This result on minority-owned business applicants would suggest noncompliance with the ECOA and require corrective action by the lender.

The third column of Table 4 contains results for the model without the three test variables. These results are provided for two reasons. First, they allow us to see the additional explanatory power of race, ethnicity, and gender in our model, which is modest

\footnotetext{
${ }^{10}$ It may be that our model includes variables that are different from those used by actual lenders. However, if our control variables are highly correlated with the variables used by the lender, they will exhibit statistically significant parameter estimates and contribute to a higher model $\mathrm{R}^{2}$.

${ }^{11}$ In addition to the control variables listed in Table 2 , the reported tests also included binary variables for each one-digit SIC code to see whether firms in different industries experienced different lending decisions. The parameter estimates for these variables are not listed in Table 4, as none of them are significant at any conventional level. We also performed separate tests with controls for geographic region These tests are not reported because none of the regional dummies was significant at any conventional level.

${ }^{12}$ For example, female-owned businesses are much smaller and younger than white-male-owned businesses. As we noted earlier, size and age are proxies for credit quality, so it appears that female-owned businesses are denied credit more frequently than white-male-owned businesses for rational economic reasons. Lenders should be careful not to use this "rational basis" argument too freely. The law states that even if an underwriting standard is nondiscriminatory on its face, it can be disallowed if it has a disparate impact on a protected class.
}

as the pseudo- $\mathrm{R}^{2}$ rises from 18.59 percent to only 19.52 percent when the test variables are included. The female and Hispanic test variable parameters are insignificant, so only the minority variable contributes to the improved $R^{2}$. However, the small improvement in explanatory power indicates that, while minority-owned businesses are less likely to have loan applications accepted, race is not a primary factor in the loan decision process. Second, a comparison of the coefficients across columns 2 and 3 of Table 4 shows that the parameter estimates are consistent. This assures us that the significance of the coefficient on the minority variable is not due to a collinearity problem between control variables. ${ }^{13}$

\section{Problems with Regression Results}

In the previous section our results suggest that, after controlling for the credit evaluation process with our credit quality variables, businesses owned by females and Hispanics have similar access to credit as firms owned by white males. However, our results suggest that, even after careful control for the credit evaluation process, businesses owned by minorities have less access to credit than other businesses of similar credit quality. This result does not support complete lender compliance with the ECOA. But the result may come from one or more problems with the tests.

Let's retrace the steps we took to get to this point to see whether we can find any place where a problem may have occurred. The primary issue is whether traditionally underserved groups have the same access to credit as the majority. Our loan process data include loan applications from many businesses, including businesses owned by traditionally underserved groups-females, minorities, and Hispanics. Following the lead of previous studies on credit access, we define the majority group to be businesses owned by white males. Next, we determine that lenders make loans to applicants that the lender believes will have adequate future cash flow to repay the loan in accordance with the loan contract and have other indications of high credit quality. We identify a set of credit quality variables that we use in the lending decision process and make sure that each variable has an economic interpretation that warrants its inclusion as a credit quality indi-

\footnotetext{
${ }^{13}$ We performed additional tests to determine the robustness of our results. In one, we examined the interaction between gender and ethnicity. Our results suggest that ethnic group is the dominant factor; however, some combinations of gender and ethnicity were quite small (for example, only 16 firms owned by Hispanic females had usable data), so our conclusions in this regard must be considered tentative.
} 
cator. The summary statistics for the credit quality variables selected suggest that, within each demographic group, they have the expected relation to the accept/reject decision for the loan applications. Then we estimate a logistic regression model and find that the parameter estimates for credit quality variables have the expected signs, so the regression appears to work correctly. However, the final results on the test variables suggest that, while access to credit for female-owned businesses and Hispanicowned businesses is similar to that of white-maleowned businesses, access to credit for minorityowned businesses appears to be lower.

This process is correct and well conducted, yet there are a couple of questions we can ask about our regressions. First, our full-model regression (Table 4, column 2) has a pseudo- $\mathrm{R}^{2}$ statistic of only 19.52 percent. The pseudo- $\mathrm{R}^{2}$ statistic describes how much of the credit evaluation process we are able to explain with our model, which means in our case that more than 80 percent of the process remains unexplained. It may be that we have failed to include information about the loan applicant that is relevant to the credit decision. Such a scenario is often referred to as an omitted variable problem and is a particular concern for self-monitoring by individual lenders. Specifically, if the model is developed correctly, as it was here, there is no indication of where to find the omitted variable(s). In addition, adding new variables to the model and testing their significance takes a great deal of time for data collection, if it is even possible, as there is a good chance that the data in question were not collected beforehand.

In our case, working with the survey data allowed us to include other variables easily, but we were unable to find any that could explain more of the credit evaluation process. That is, we were unable to find additional economic variables that added substantially to our ability to explain the lending process, let alone ones that helped to explain why minority-owned businesses are less likely to have a loan request approved than otherwise similar whitemale-owned businesses. An issue related to the omitted variable problem is how to specify each variable. For example, we use total assets as our measure of firm size, but we specify the variable as the natural logarithm of total assets $(\ln (t a))$. Another common adjustment is to scale a dollar figure so that it is a percentage of the firm's total assets or sales (e.g., we specify inventory and accounts receivable as a percentage of total assets).
In this case, we tried various variable definitions, and we report only the definitions for the best model (the model that explains the most about the credit evaluation process). ${ }^{14}$

A second possible problem with regression analysis for an individual lender is sample size. The minimum acceptable sample size for a statistical test on one variable is about 30 observations. However, for a regression model like ours with 18 control and 3 test variables, we should have at least 51 loan applications (30 plus the number of test and control variables) for each regression, with a balance between the underserved group and the majority. This is not a problem for our regression on minorityowned businesses, as Table 1 shows that our minorityowned sample contains 257 businesses. However, we can provide an example of the sample-size problem from the survey data. An additional survey variable allowed us to separate Native Americanowned businesses from the full sample of minorityowned businesses. The Native American subsample contained only ten observations (eight approved and two denied), so regression analysis on this group of businesses using our model would not be appropriate. The small sample size of the Native Americanowned businesses in the survey data demonstrates the potential for sample-size problems. It is easy to imagine that most small lenders would have difficulty achieving the necessary sample size for some underserved groups. There is no direct solution to this problem for an individual lender.

The two potential problems described above are not problems in our analysis. This means that our lender is left with the need to make adjustments to their credit analysis process so that minorityowned businesses get equal access to credit. This won't be easy because the answer won't be obvious. Remember, while the minority variable parameter estimate is statistically significant, having the minority variable in the regression model added only a little to the model's ability to explain the credit evaluation process. So a lender will need to adjust its process so that the marginal minority-owned business loan applicants get the same access to credit

\footnotetext{
${ }^{14}$ We also need to be careful not to try too many versions of a single variable. Our indicator of statistical significance ( $p$-value $\leq 0.10)$ allows for possible error. For example, a p-value exactly equal to 0.05 means that we are 95 percent confident the true parameter value is not 0 but admit a 5 percent probability of being wrong. If we try more than one version of a particular variable and only one version exhibits a significant $\mathrm{p}$-value, our probability of having made an error is significantly larger than indicated by the $\mathrm{p}$-value. The problems related to trying multiple versions of the same variable and multiple combinations of control variables are grouped under the name "data snooping."
} 
as the marginal white-male-owned businesses. In other words, a lender must make sure that, when giving "the benefit of the doubt" to marginal applicants, this benefit is given equally across all demographic groups.

\section{A POSITIVE ROLE FOR BANK EXAMINERS AND REGULATORS IN THE SELF-MONITORING PROCESS}

The process that we have discussed for selfmonitoring is relatively straightforward and appears to address the issue of compliance with the ECOA. Unfortunately, compliance is not that simple, which is why we believe that there is an important role in the self-monitoring process for bank examiners and regulators. The reason is that some of the problems that exist in self-monitoring cannot be corrected by an individual lender.

First, many lenders, particularly smaller lenders, will encounter sample-size problems, just as we did in our example with respect to Native Americanowned businesses. An individual lender's test sample is limited to the number of loan applications that the lender has processed, and for many small lenders this will provide an insufficient number of observations for regression analysis on some or all of the traditionally underserved groups. Bank examiners and regulators can do nothing to correct this problem on an individual lender basis. However, the newly collected demographic data, when combined with regulators and examiners' ability to monitor lending across the United States, will illuminate patterns not visible to individual lenders. If the need arises, regulators and examiners will be able to spread the word that a certain group or set of groups appears to be suffering from lending discrimination, despite controls for credit quality, allowing individual institutions to enhance their internal efforts.

Second, the only concern uncovered by our analysis is in providing equal access to credit for minority-owned businesses. However, outside research suggests that we missed some more subtle forms of limited access to credit for traditionally underserved groups. Cavalluzzo, Cavalluzzo, and Wolken (2002) use the same survey data that we use and show striking loan denial rate differences in less-competitive markets. In the least competitive banking markets, they find a denial rate for whitemale-owned businesses of 27 percent accompanied by a 55 percent denial rate for minority-owned businesses. In addition, they show that in lesscompetitive banking markets, female-owned busi- nesses are denied at a rate of 37 percent, whereas white-male-owned businesses are denied at a rate of 23 percent. They found these additional problems with equal credit access by using more advanced regression models ${ }^{15}$ along with data on the level of local banking market competition. Data across lending markets is not directly available to individual lenders, so they would not be able to conduct this sort of analysis in their self-monitoring process. In addition, lenders in the less-competitive markets are typically the smaller lenders; so small sample sizes for the underserved groups are a likely problem. With a national (or regional) focus and access to cross-lender data, supervisors and regulators can see problems not visible to individual lenders.

Finally, as self-monitoring becomes prevalent, a number of lenders will begin to employ unfamiliar statistical tools (such as those described in this article). The examination process provides an opportunity for the lenders to ask knowledgeable sources about various statistical tools, models, and approaches to self-monitoring. Thus, the third role for regulators and examiners is to serve as sources of advice and information to lenders as they begin their self-monitoring efforts.

\section{CONCLUSION}

Reg B has been modified to allow lenders to collect demographic data on all loan applicants so they can self-monitor their compliance with ECOA requirements. Because this will be a new endeavor for most lenders, the purpose of this article is to discuss how individual lenders can self-monitor their compliance. We provided an example of this process using data from the 1993 Survey of Small Business Finances. In addition to describing the process, we discussed possible problems with our approach, particularly noting omitted variables and small sample size. We also discussed why regulatory oversight of self-monitoring is useful.

\section{REFERENCES}

Avery, Robert B.; Bostic, Raphael W. and Samolyk, Katherine A. "The Role of Personal Wealth in Small Business Finance." Journal of Banking and Finance, August 1998, 22(6-8), pp. 1019-61.

\footnotetext{
${ }^{15}$ Cavalluzzo, Cavalluzzo, and Wolken (2002) use interactive variables between the underserved groups and a measure of local banking market competition. While interactive variables are relatively easy to create and estimate in a regression model, the interpretation of these variables can be tricky and, we believe, likely beyond the comfort level of most lenders.
} 
Berger, Allen N. and Udell, Gregory F. "Relationship Lending and Lines of Credit in Small Firm Finance." Journal of Business, July 1995, 68(3), pp. 351-81.

and "The Economics of Small Business Finance: The Roles of Private Equity and Debt Markets in the Financial Growth Cycle." Journal of Banking and Finance, August 1998, 22(6-8), pp. 613-73.

Blackwell, David W. and Winters, Drew B. "Banking Relationships and the Effect of Monitoring on Loan Pricing." Journal of Financial Research, Summer 1997, 20(2), pp. 275-89.

and "Local Lending Markets:

What a Small Business Owner/Manager Needs to Know." Quarterly Journal of Business and Economics, Spring 2000, 39(2), pp. 62-79.

Cavalluzzo, Ken S. and Cavalluzzo, Linda C. "Market Structure and Discrimination: The Case of Small Businesses." Journal of Money, Credit, and Banking, November 1998, 30(4), pp. 771-92.

and Wolken, John D. "Competition, Small Business Financing, and Discrimination: Evidence from a New Survey." Journal of Business, October 2002, 75(4), pp. 641-79.

Elliehausen, Gregory E. and Lawrence, Edward C. "Discrimination in Consumer Lending." Review of Economics and Statistics, February 1990, 72(1), pp. 156-60.

Hunter, William C. and Walker, Mary Beth. "The Cultural Affinity Hypothesis and Mortgage Lending Decisions."
Journal of Real Estate Finance and Economics, July 1996, 13(1), pp. 57-70.

Koch, Timothy W. Bank Management. Third Edition. Orlando: Dryden Press, 1995, pp. 662-93.

Melnik, Arie L. and Plaut, Steven E. "Loan Commitment Contracts, Terms of Lending, and Credit Allocation." Journal of Finance, June 1986, 41(2), pp. 425-35.

Munnell, Alicia H.; Tootell, Geoffrey M.B.; Browne, Lynn E. and McEneaney, James. "Mortgage Lending in Boston: Interpreting HMDA Data." American Economic Review, March 1996, 86(1), pp. 25-53.

Nesiba, Reynold F. "Racial Discrimination in Residential Lending Markets: Why Empirical Researchers Always See It and Economic Theorists Never Do." Journal of Economic Issues, March 1996, 30(1), pp. 51-77.

Petersen, Mitchell A. and Rajan, Raghuram G. "The Benefits of Lending Relationships: Evidence from Small Business Data." Journal of Finance, March 1994, 49(1), pp. 3-37.

and "The Effect of Credit Market Competition on Lending Relationships." Quarterly Journal of Economics, May 1995, 110(2), pp. 407-43.

Peterson, Richard L. "An Investigation of Sex Discrimination in Commercial Banks' Direct Consumer Lending." Bell Journal of Economics, Autumn 1981, 12(2), pp. 547-61.

Saunders, Anthony. Credit Risk Measurement: New Approaches to Value at Risk and Other Paradigms. First Edition. New York: John Wiley, 1999.

\section{Appendix}

To provide empirical results for each step, we use a cross-section of small business lending decisions reported in the 1993 Survey of Small Business Finances that was conducted by Price Waterhouse for the Board of Governors of the Federal Reserve System. The survey contains usable responses (according to Price Waterhouse) for 4,637 firms.

An earlier version of this survey done in 1987 was the focus of a number of important studies, including the following: Petersen and Rajan (1994), which found that small businesses benefit from building close ties to a financial institution; Petersen and Rajan (1995), which found that concentration in the market for financial institutions adversely impacts the amount of institutional finance received by young firms; and Berger and Udell (1995), which found that borrowers with more established banking relationships pay lower interest rates and are less likely to pledge collateral. The survey done in 1993 was examined in Berger and Udell (1998), which showed how capital structure and sources of capital vary with firm size and age, and in Avery, Bostic, and Samolyk (1998), which compared the 1987 and 1993 surveys and found that personal guarantees by small business owners play a growing role in the allocation of credit. 
